\title{
Endocrine and ovarian follicular changes leading up to the first ovulation in prepubertal heifers
}

\author{
A. C. O. Evans ${ }^{1}$, G. P. Adams ${ }^{2}$ and N. C. Rawlings ${ }^{1 *}$ \\ Departments of ${ }^{\mathrm{I}}$ Veterinary Physiological Sciences and ${ }^{2}$ Veterinary Anatomy, Western College \\ of Veterinary Medicine, University of Saskatchewan, Saskatoon, Saskatchewan, S7N OWO, \\ Canada
}

\begin{abstract}
Changes in the pattern of follicular growth and development, and the associated endocrine changes, were examined in prepubertal heifers approaching their first ovulation. Ten, age-matched ( \pm 3 days), Spring-born Hereford heifers were examined daily by transrectal ultrasonography for 17 days beginning 12 weeks before the first ovulation, and daily from just before the first ovulation until the completion of one normal duration ovulatory cycle. On each day of ultrasound examination, the position and diameter of corpora lutea and follicles $\geqslant 3 \mathrm{~mm}$ in diameter were recorded, and one blood sample was collected. Blood samples were also collected every $15 \mathrm{~min}$, for $12 \mathrm{~h}$, at 20,12 and 4 weeks before the first ovulation, to assess the pulsatile nature of LH and FSH secretion. The first ovulation occurred at $56.0 \pm 1.2$ weeks of age, at a body weight of $391.9 \pm 12.0 \mathrm{~kg}$. Waves of follicular development, similar to those of adult cows, were seen at all ages, and in all heifers, the first ovulation was followed by an ovulatory cycle of short duration $(7.7 \pm 0.2$ days) and then by a normal duration ovulatory cycle (20.3 \pm 0.5 days). The maximum diameter of the dominant, or largest subordinate, follicles did not increase as the first ovulation approached, or during the subsequent ovulatory cycles. Similarly, there were no differences between follicle growth rates $\left(1.4 \pm 0.1 \mathrm{~mm}\right.$ day $^{-1}$ ) or regression rates $(1.2 \pm 0.1 \mathrm{~mm}$ $\mathrm{day}^{-1}$ ) as the animals matured, and the interwave interval increased up to the first ovulation. Waves of follicular development were associated with peaks in FSH concentrations at 12 weeks before the first ovulation. The short duration, ovulatory cycle was associated with low progesterone concentrations and small corpora lutea (mean maximum values $2.75 \pm 0.66 \mathrm{ng} \mathrm{ml}^{-1}$ and $19.9 \pm 2.0 \mathrm{~mm}$, respectively), compared with normal cycle durations (10.15 $\pm 0.58 \mathrm{ng} \mathrm{ml}^{-1}$ and $25.8 \pm 0.8 \mathrm{~mm}$ ). Mean serum oestradiol and $\mathrm{LH}$ concentrations and LH pulse frequency increased as the first ovulation approached, but FSH concentrations did not. We conclude that, in heifers before the first ovulation, growth and regression of large follicles occur in a wave-like pattern, with characteristics and associated patterns of gonadotrophin secretion similar to those seen in adult, cyclic animals. Hence, in late prepubertal heifers, factors controlling follicle growth are in place, and there are no changes in these parameters in the three months preceding the first ovulation.
\end{abstract}

\section{Introduction}

Endocrine and ovarian changes leading up to the first ovulation in heifers are not fully understood. In the two months preceding puberty, it has been shown that mean, circulating concentrations of $\mathrm{LH}$ and $\mathrm{LH}$ pulse frequency increase (Day et al., 1984; Kinder et al., 1987). Similar observations were made in ewes (Rawlings and Churchill, 1990) and gilts (Lutz et al., 1984). It was suggested that this increase in LH secretion occurred as a result of a decrease in sensitivity to ovarian oestradiol negative feedback (Day et al., 1987). Studies of

*Reprint requests.

Received 29 March 1993. ovarian follicular development during the period of sexual maturation have been confined to the examination of tissues collected at slaughter (Erickson, 1966; Desjardins and Hafs, 1969). With the use of real-time ultrasonography, it has been shown that, during the ovulatory cycles of sexually mature cows, follicular development occurs in waves (Pierson and Ginther, 1988; Savio et al., 1988; Sirois and Fortune, 1988). A follicular wave was characterized as the synchronous development of a group of follicles, one of which became dominant and achieved the greatest diameter, suppressing the growth of the other smaller subordinate follicles. In heifers, near the time of first ovulation (age not stated), the sequential growth and regression of large follicles have been detected using transrectal ultrasonography (Roche and Boland, 1991). In a recent study, 
of eight-month-old heifers, daily changes in follicle diameter and numbers were described (Adams et al., 1994); ovarian follicles grew and regressed in a wave-like pattern, and on the basis of comparisons with follicular dynamics in mature cows (Ginther et al., 1989), it was concluded that follicular development changed in a quantitative, not a qualitative, manner as the heifers approached first ovulation. This hypothesis was tested in the present study.

The aim of this study was to examine ovarian follicular development in the three months before the first ovulation, and during the first two ovulatory cycles, and also to correlate ovarian changes with changes in circulating concentrations of $\mathrm{LH}, \mathrm{FSH}$, oestradiol and progesterone.

\section{Materials and Methods}

\section{Animals and procedures}

Ten, Hereford heifer calves (born 4 April \pm 3 days) were weighed every two weeks from birth. Calves were suckled at pasture until weaning at 20 weeks old, and they were then kept in a paddock and given hay, water and a concentrate ration ad libitum.

Heifers were examined during two observational periods starting at 44 and 52 weeks of age (data from an observational period starting at 36 weeks of age have been reported (Adams et al., 1994)). During each observational period, ovaries were examined daily by transrectal ultrasonography using a $7.5 \mathrm{MHz}$ linear-array transducer connected to a B-mode scanner (Aloka SSD-500, Overseas Monitor Corporation Ltd, Richmond, BC). Each day the position, diameter and number of individually identified ovarian follicles, $\geqslant 3 \mathrm{~mm}$ in diameter, and corpora lutea were recorded, as described for prepubertal heifers (Adams et al., 1994) and sexually mature heifers (Knopf et al., 1989). At 44 weeks of age, observations were made for 17 days, as this period was found to encompass the emergence of two successive waves of follicular development in 8-monthold heifers (Adams et al., 1994). Starting from 52 weeks of age, the heifers were examined daily until their third ovulation was detected, or for 90 days, whichever period was shortest. The first ovulation was expected, at about 56 weeks of age, based on a previous study (Evans et al., 1992).

During each daily ultrasound examination, a single blood sample was drawn by jugular venepuncture. At 44 weeks of age, serum was collected; from 52 weeks, daily samples were collected into heparinized tubes. From 48 to 52 weeks of age, heparinized blood samples were also collected once a week. Heparin was used to allow immediate centrifugation and collection of plasma to prevent the metabolism of progesterone. At 36 weeks of age and at 8 days after the start of each period of daily ultrasound examination, heifers were fitted with indwelling jugular vinyl catheters (Dural Tubing, i.d. $1.0 \mathrm{~mm}$, o.d. $1.5 \mathrm{~mm}$; Critchley Electrical Products, Dural, NSW), and I day later, blood samples were collected every $15 \mathrm{~min}$ for $12 \mathrm{~h}$, to characterize the pulsatile nature of $\mathrm{LH}$ and FSH secretion. In the period of ultrasound examination starting at 52 weeks of age, only heifers that had not ovulated were intensively bled. All plasma and serum samples were stored at $-20^{\circ} \mathrm{C}$ until analysis.

\section{Radioimmunoassays}

All serum and plasma samples were analysed for concentrations of LH and FSH by validated double antibody radioimmunoassays (Rawlings et al., 1984; Evans et al., 1992). LH concentrations are expressed in terms of NIDDK-bLH4. The range of the standard curve was from 0.06 to $8 \mathrm{ng} \mathrm{ml}^{-1}$. The sensitivity of the assay was $0.1 \mathrm{ng} \mathrm{ml}^{-1}$; this was the lowest concentration of unlabelled $\mathrm{LH}$ that could displace iodinated LH from the first antibody $(P<0.05$ by $t$ test). Intra- and interassay coefficients of variation were $8 \%$ and $14 \%$ (mean $=0.70 \mathrm{ng} \mathrm{ml}^{-1}$ serum) and $7 \%$ and $12 \%$ (mean $=3.07 \mathrm{ng} \mathrm{ml}^{-1}$ serum), respectively, for reference sera included in every assay. For the FSH assay, the first antibody used was NIDDK-anti-oFSH-1, and concentrations are expressed in terms of USDA-bFSH-I1. The range of the standard curve was 0.13 to $16 \mathrm{ng} \mathrm{ml}^{-1}$. The sensitivity of the assay was $0.2 \mathrm{ng} \mathrm{ml}^{-1}(P<0.05)$. Intra- and interassay coefficients of variation were $8 \%$ and $15 \%$ (mean $=1.41 \mathrm{ng} \mathrm{ml}^{-1}$ serum) and $6 \%$ and $11 \%$ (mean $=3.45 \mathrm{ng} \mathrm{ml}^{-1}$ serum), respectively.

All plasma samples were analysed for progesterone (Rawlings et al, 1984). The range of the progesterone standard curve was 0.1 to $10 \mathrm{ng} \mathrm{ml}^{-1}$; the sensitivity of the assay was $0.1 \mathrm{ng} \mathrm{m} \mathrm{m}^{-1}$ plasma. Intra- and interassay coefficients of variation were $10 \%$ and $13 \%$ (mean $=0.74 \mathrm{ng} \mathrm{ml}^{-1}$ plasma) and $8 \%$ and $10 \%$ (mean $=3.67 \mathrm{ng} \mathrm{ml}^{-1}$ plasma).

All serum and plasma samples, collected daily, were analysed for oestradiol by radioimmunoassay (Joseph et al., 1992). The range of the standard curve was $1-100 \mathrm{pg} \mathrm{ml}^{-1}$ and the assay sensitivity was $1 \mathrm{pg} \mathrm{ml}^{-1}$ serum. Intra- and interassay coefficients of variation were $6 \%$ and $14 \%$ (mean $=14.1 \mathrm{pg} \mathrm{ml}^{-1}$ serum) and $4 \%$ and $11 \%$ (mean $=24.1 \mathrm{pg} \mathrm{ml}^{-1}$ serum).

\section{Statistical analysis}

A detailed statistical analysis of follicular dynamics in the prepubertal heifer at 8 months of age has been made; it was concluded that follicle growth and regression was wave-like (Adams et al., 1994). That study was based on observations in the heifers used in the present study. In the study reported here, only data collected for waves detected in their entirety (with growing, static and regressing phases) were used for statistical analysis. The waves were classified as those at 12 weeks before the first ovulation (44 weeks of age), the last non-ovulatory wave before the first ovulation, the first ovulatory wave, the second ovulatory wave (first short cycle), and the subsequent two or three waves of follicular development during the first ovulatory cycle of normal duration. The growth curve for the largest follicle of a wave was considered in three sections: the growing phase, the static phase and the regression phase (Ginther et al, 1989). The day of emergence of a wave was defined as the last day, on which the follicle destined to become the largest follicle, for that wave, was retrospectively identified at a diameter of 4 or $5 \mathrm{~mm}$. The growing phase of a follicle was defined as the period between its emergence and the day on which it appeared to stop its progressive increase in diameter. The regression phase was defined as the period between the day that the follicle began its progressive decrease in diameter and the day that it first reached 4 or $5 \mathrm{~mm}$ in 


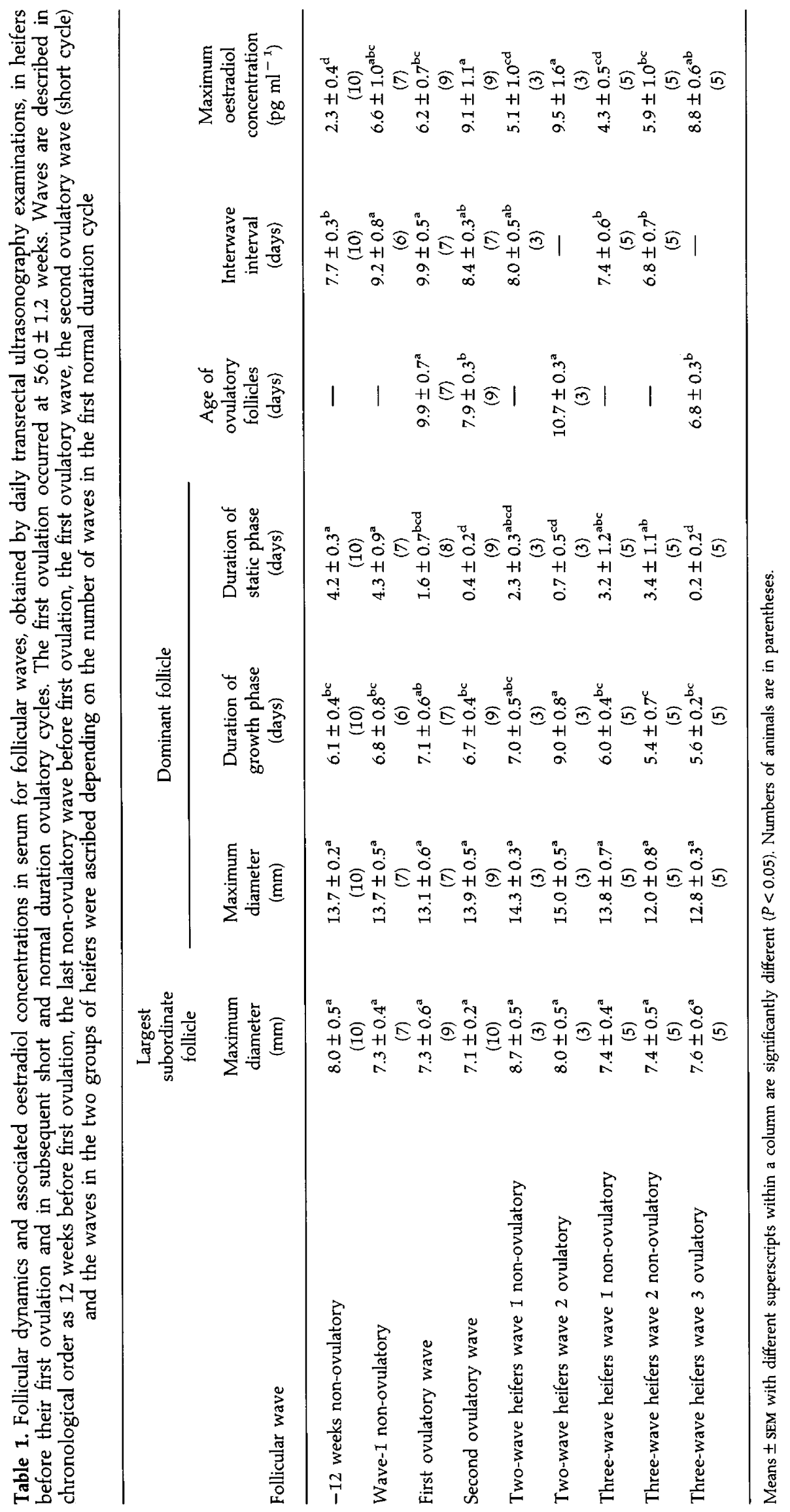



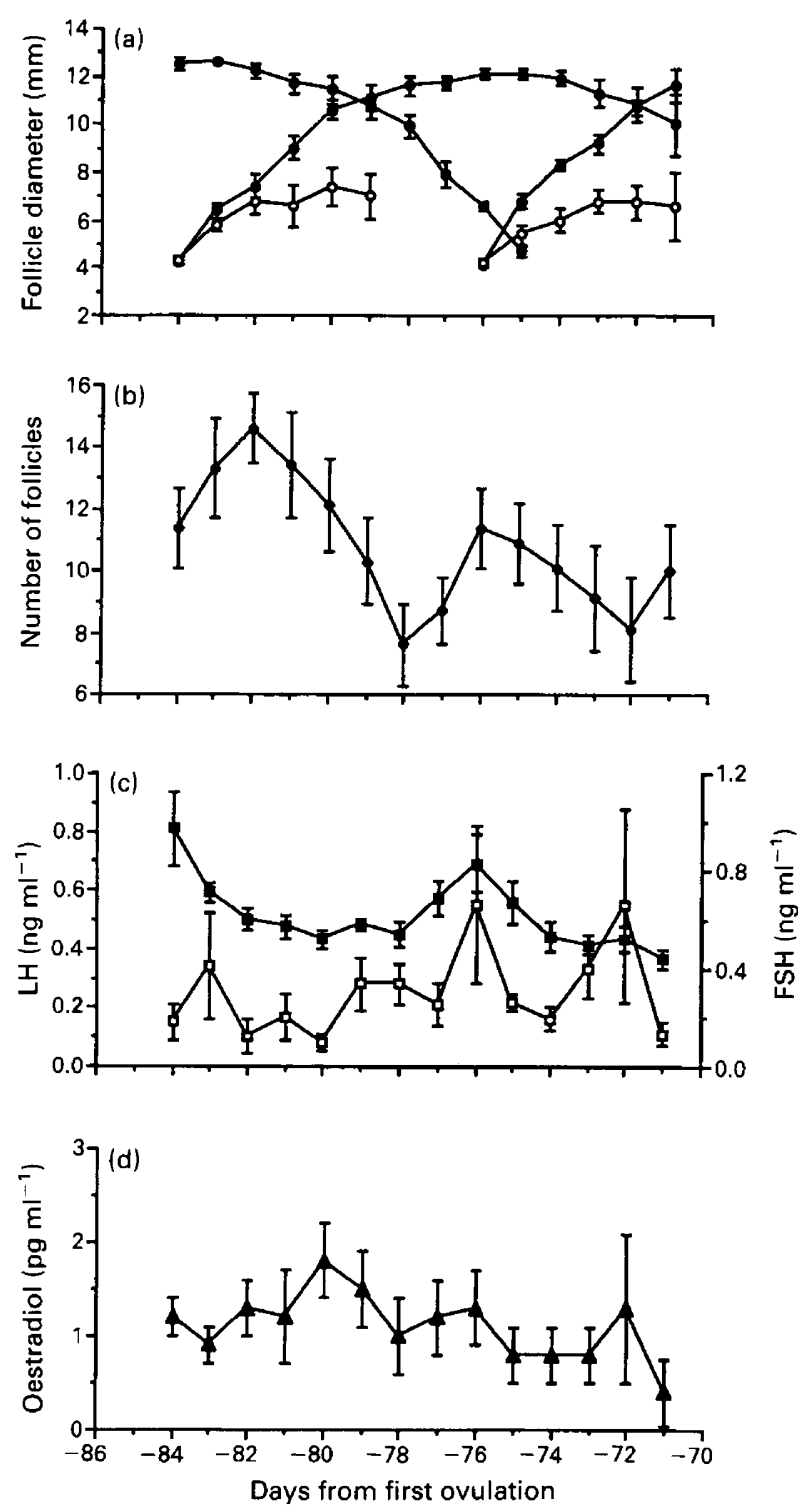

Fig. 1. Mean ( \pm SEM) diameters for (a) the dominant $(\bigcirc)$ and largest subordinate follicles $(O)$ for each wave of follicular development observed in heifers by daily transrectal ultrasonography at 12 weeks before the first ovulation (44 weeks old). Mean ( \pm SEM) numbers of (b) follicles $\geqslant 4 \mathrm{~mm}$ in diameter, and concentrations of (c) $\mathrm{LH}$ ( $\square$ ) and FSH ( $)$, and (d) oestradiol aligned to waves of follicular development.

diameter. The static phase was defined as the period between the end of the growing phase and the beginning of the regressing phase (Ginther et al., 1989). An interwave interval was defined as the number of days between the emergence of two consecutive follicles that were destined to become the largest for consecutive waves. Ovulations were identified as the first day on which the largest follicle of a wave disappeared and was followed by the development of a corpus luteum at that site on the ovary.

To produce data, and to align the endocrine data to the follicle data, the follicle data were normalized (similar waves between animals were overlaid). This was done by aligning the growth profiles of the largest follicles to their mean day of emergence. Numbers of follicles $\geqslant 4 \mathrm{~mm}$ in diameter were also aligned to the day of emergence of the largest follicles. The endocrine data were aligned to the follicle data, such that they matched the normalized follicle profiles. Consecutive follicular waves were placed at a mean interwave interval, and the associated data for number of follicles and hormones realigned with them. Follicular development was described as being wave-like, if there were significant $(P<0.05)$ increases in follicle numbers ( $\geqslant 4 \mathrm{~mm}$ in diameter) associated with the growth of large antral follicles (Adams et al., 1994). In samples collected daily, a peak of FSH or LH was defined as a significant increase $(P<0.05)$ in the profiles normalized to the emergence of large antral follicles (Adams et al., 1992).

The pulsatile secretion of LH and FSH was determined for the $12 \mathrm{~h}$ in which serum samples were collected every $15 \mathrm{~min}$ at 36, 44 and 52 weeks of age, using PC-Pulsar (J. Gitzen and $V$. Ramirez, University of Illinois). Pulses were identified using standard deviation criteria (Merriam and Wachter, 1982) and basal concentrations were determined by subtraction of pulses from the profile. Circulating patterns are expressed as basal and mean circulating concentrations, pulse amplitude and pulse frequency.

Data were statistically analysed using repeated measures analysis of variance and split plot analysis of variance (SAS Version 6, SAS Institute Inc., Cary, North Carolina), with least significant difference as the post-ANOVA test. Comparisons were made of the growth characteristics of individual dominant follicles for each wave of follicular development amongst ages. All data are presented as the mean \pm SEM.

\section{Results}

\section{Ovarian follicles}

The mean age at the first ovulation, as determined by transrectal ultrasonography, was $56.0 \pm 1.2$ weeks, at a body weight of $391.9 \pm 12.0 \mathrm{~kg}$. The observation period that started at 44 weeks was on average 12 weeks before the first ovulation. At all ages, the growth and regression of large follicles were seen in a wave-like pattern. One heifer had already ovulated before the start of the observation period, at 52 weeks of age, and was estimated to have done so within 7 days on the basis of serum progesterone concentrations. After first ovulation, all of the heifers underwent a short ovulatory cycle ( $7.7 \pm 0.2$ days), accompanied by one wave of follicular development. This was followed by an ovulatory cycle of normal duration (20.3 \pm 0.5 days; $P=0.0001)$. Two of the heifers had only completed one short cycle before the end of the 90 day period of observation. Of the eight heifers that completed an ovulatory cycle of normal duration, three had two waves of follicular development (two-wave heifers) and five had three waves of follicular development (three-wave heifers) during their cycles.

There were no significant changes in the maximum diameter of the dominant or largest subordinate follicles, as heifers reached first ovulation, or during subsequent ovulatory cycles of short or normal duration $(P>0.25)$. There was also no 


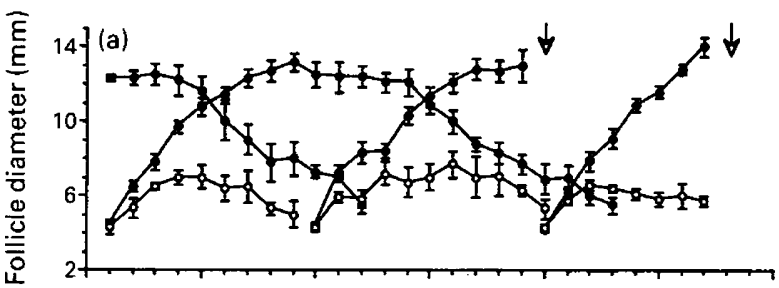

(b)
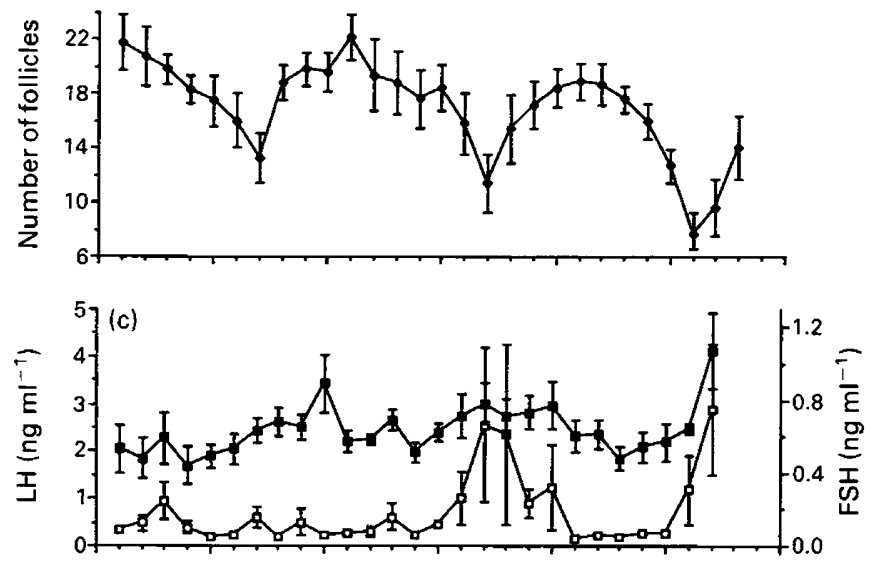

(d)

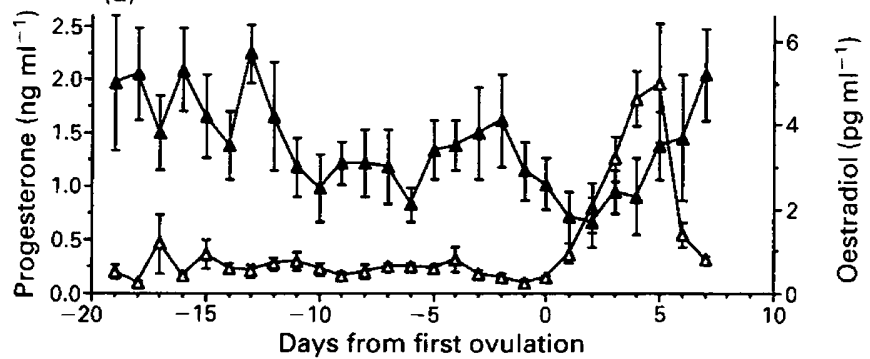

Fig. 2. Mean ( \pm SEM) diameters for (a) the dominant (O) and largest subordinate follicles $(O)$ for each wave of follicular development observed in heifers by daily transrectal ultrasonography at the time of first ovulation (56.0 \pm 1.2 weeks of age). Mean ( \pm SEM) numbers of (b) follicles $\geqslant 4 \mathrm{~mm}$ in diameter, and concentrations of (c) $\mathrm{LH}(\square)$ and FSH $(\boldsymbol{D})$, and (d) progesterone $(\triangle)$ and oestradiol $(\boldsymbol{\Delta})$ aligned to waves of follicular development. Arrows indicate the mean day of ovulation.

difference between waves for the ratio of the maximum diameters of the largest subordinate follicle to the dominant follicle $(P=0.45)$ with the subordinate follicle being $65.0 \pm 1.1 \%$ of the diameter of the dominant follicle. There were no differences between dominant follicle growth rates at any of the ages studied (mean $1.4 \pm 0.1 \mathrm{~mm}^{-1 a y}{ }^{-1} ; P=0.25$ ) or regression rates (mean $1.2 \pm 0.1 \mathrm{~mm}^{-1}{ }^{-1} ; P=0.55$ ), or of the duration of regression $(7.5 \pm 0.8$ days; $P=0.07)$. Few differences were seen between waves in the duration of dominant follicle growth (Table 1 ); the ovulatory wave, during the cycle of normal duration of the heifers with two waves of follicular development per cycle, showed the longest growing phase $(9.0 \pm 0.8$ days), and the growing phase of the second wave of the cycle of normal duration of the three-wave heifers was the shortest $(5.4 \pm 0.7$ days; $P<0.05)$. The duration of the static phases was longer for the non-ovulatory waves than for the ovulatory waves $(P<0.05$; Table 1$)$. The interval between the emergence of the last non-ovulatory and first ovulatory follicle, and the first and second ovulatory follicles was longer than the interwave interval at 12 weeks before first ovulation, and the interwave intervals during the cycle of normal duration for heifers with three waves of follicular development $(P<0.05$; Table 1$)$. The ages of the ovulatory follicles were similar between the first ovulation and the ovulation of the cycle of normal duration of the two-wave heifers, but the second ovulation of the short cycle and the ovulatory follicle of the cycle of normal duration of the three-wave heifers were shorter $(P<0.05$; Table 1$)$. The maximum diameter of the corpora lutea was less $(19.9 \pm 2.0 \mathrm{~mm})$ for the short cycles than for the cycles of normal duration $(25.8 \pm 0.8 \mathrm{~mm}, P<0.02)$. During the short and normal duration cycles, corpora lutea, with and without central cavities, were seen. 

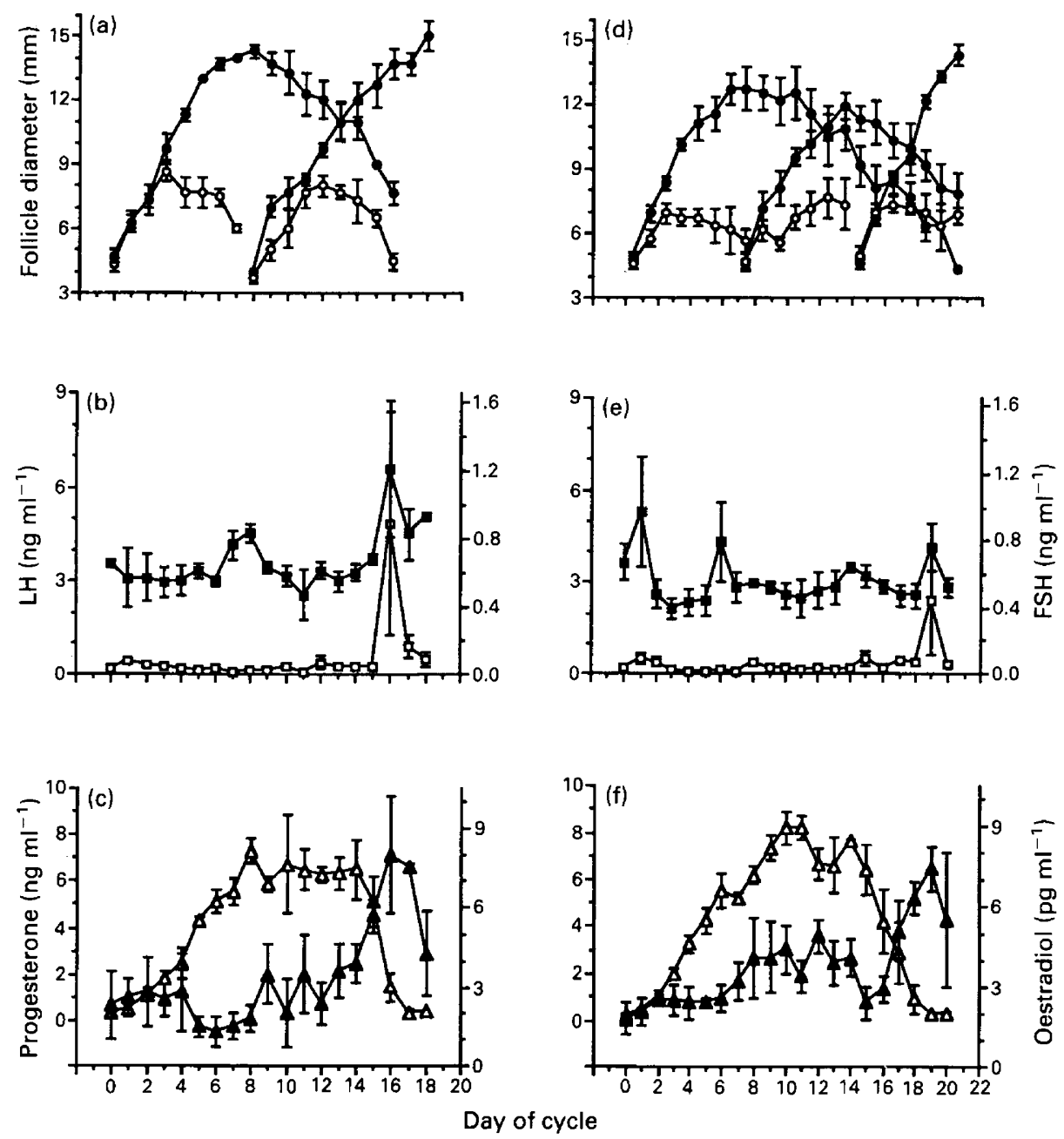

Fig. 3. Follicle and endocrine changes for heifers with two waves $(a, b, c ; n=3)$ and three waves (d, e, $f ; n=5$ ) of follicular development in the first cycle of normal duration after the first ovulation determined by daily ultrasound examinations and from daily plasma samples. Mean ( \pm SEM) diameters of the dominant $(O)$ and largest subordinate $(O)$ follicles and mean $( \pm$ SEM) circulating concentrations of $\mathrm{LH}(\square)$ and FSH $(\boldsymbol{\square})$, oestradiol $(\boldsymbol{\Delta})$ and progesterone $(\triangle)$.

\section{Circulating hormones}

Serum concentrations of FSH increased to a peak on the day of wave emergence at 12 weeks before the first ovulation (Fig. $1 ; P<0.05$ ). No other significant changes in mean FSH concentrations or any significant changes in mean serum concentrations of LH were seen $(P<0.05$; Figs 1,2 and 3$)$. Maximum oestradiol concentrations for each wave of follicular development were lowest at 12 weeks before the first ovulation, and increased thereafter, with highest concentrations associated with ovulatory follicles of normal duration cycles $(P<0.05$; Table 1$)$. There were no significant trends in serum oestradiol concentrations associated with waves of follicular development, at 12 weeks before the first ovulation $(P>0.80$; Fig. 1), but oestradiol concentrations did increase before ovulations $(P<0.05$; Figs 2 and 3 ). Mean plasma progesterone concentrations were increased on 3 days during the short cycle (Fig. 2) and for 11 and 12 days for the cycles of normal duration of the two- and three-wave heifers, respectively,
(Fig. 3; $P<0.05$ ). Maximum, circulating progesterone concentrations were greater for cycles of normal duration than for cycles of short duration $\left(10.15 \pm 0.58 \mathrm{ng} \mathrm{ml} \mathrm{m}^{-1}\right.$ versus $2.75 \pm 0.55 \mathrm{ng} \mathrm{ml}^{-1} ; \mathrm{p}=0.0001$ ).

Blood samples were taken every $15 \mathrm{~min}$ for $12 \mathrm{~h}$ at 20,12 and 4 weeks before the first ovulation (36, 44 and 52 weeks of age). At the last sampling period three heifers had already ovulated; the remaining seven were $4.4 \pm 1.2$ weeks before first ovulation. Mean and basal serum concentrations of FSH at 12 weeks before the first ovulation were greater than values at either 20 or 4 weeks before the first ovulation (Fig. $4 ; P<0.05$ ). Basal circulating LH concentrations and LH pulse frequency were greater at 4 weeks before the first ovulation than at 20 and 12 weeks before the first ovulation $(P<0.05)$. Mean LH concentrations showed a steady increase with age $(P<0.05)$. LH pulse amplitude was greatest at 12 weeks before the first ovulation than at 20 and 4 weeks before the first ovulation $(P<0.05)$. 

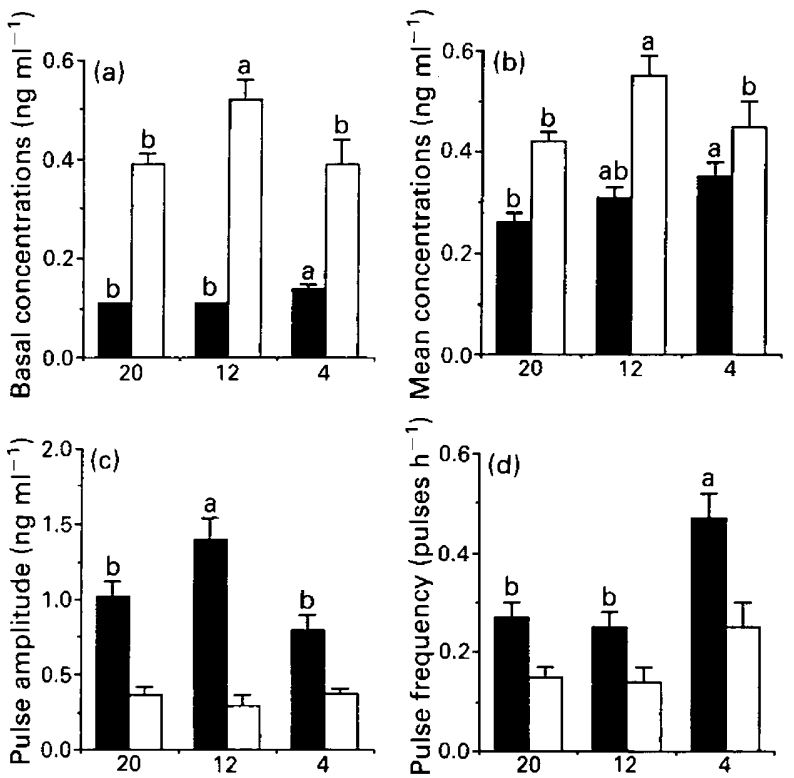

Time before first ovulation (weeks)

Fig. 4. (a) Basal and (b) mean serum concentrations of LH ( $\square$ ) and FSH ( $\square$ ), and (c) LH and FSH pulse amplitude and (d) pulse frequency in heifers bled every $15 \mathrm{~min}$ for $12 \mathrm{~h}$, at 20 weeks $(n=10)$, 12 weeks $(n=10)$ and 4 weeks $(n=7)$ before first ovulation. First ovulation occurred at $56.0 \pm 1.2$ weeks old. Significant differences between ages for each hormone are shown by different letters $(P<0.05)$.

\section{Discussion}

From the ultrasonography results, there were no predictive indicators to the exact timing of the first ovulation or to the number of waves of follicular development in the subsequent cycle of normal duration (two versus three waves). The pattern of growth and regression of follicles in the late prepubertal period and first cycles were remarkably similar to older, cyclic heifers (Sirois and Fortune, 1988; Ginther et al., 1989); it therefore appears that the mechanisms controlling follicle growth are similar between the late prepubertal period and during normal cycles. However, the maximum diameters of dominant follicles reported here were smaller than diameters reported in older heifers (Savio et al., 1988; Ginther et al., 1989), possibly reflecting breed differences, or indicating that the first ovulation is not the end of the period of reproductive development, but that maturation continues past the first ovulation.

It is unclear why the first ovulation was followed by a short cycle. The follicles giving rise to the short-lived corpus luteum, ovulated, on average, $1.6 \pm 0.7$ days into the static phase, whereas, in mature cattle, follicles ovulate at the end of, or during, the growing phase (Ginther et al., 1989). We suggest that the follicles that ovulated to give rise to a short-lived corpus luteum were in a non-growing phase for a longer period than is normally seen, and this may explain the formation of short-lived corpora lutea.

Luteal-tissue area, as determined by ultrasonography, has been positively correlated with circulating progesterone concentrations in heifers (Kastelic et al., 1990). In our study, since the corpora lutea of the short cycle were smaller (mean maximum diameter $19.9 \pm 2.0 \mathrm{~mm}$ ) and secreted less progesterone (mean maximum $2.75 \pm 0.55 \mathrm{ng} \mathrm{ml}^{-1}$ ) than did the corpora lutea of the subsequent cycle of normal duration (10.15 $\pm 0.58 \mathrm{ng} \mathrm{ml}^{-1}$; mean maximum diameter $25.8 \pm 0.8 \mathrm{~mm}$ ), it appeared that the corpora lutea of the short cycle were functionally similar to those of the cycle of normal duration, but they produced less progesterone owing to their smaller size. Short cycles of 5-7 days have been reported in pubertal heifers (Gonzalez-Padilla et al., 1975; Berardinelli et al., 1979; Dodson et al., 1988) and in postpartum cows (Perry et al., 1991). The reason for the lack of growth, small size and short lifespan of these corpora lutea is unclear. Data presented here showed small (up to $0.5 \mathrm{ng} \mathrm{ml}^{-1}$ ) increases in progesterone concentrations before the first ovulation, but associated with waves of follicular development. This progesterone could result from partial luteinization of non-ovulatory follicles, and may have played a part in the timing and stimulation of the first preovulatory surge of gonadotrophins leading to the first ovulation.

Changes in plasma concentrations of FSH have been associated with waves of follicular development during ovulatory cycles of mature heifers (Adams et al., 1992). In the study reported here, waves of follicular development, before and after the first ovulation, were associated with similar transient peaks in circulating concentrations of FSH about the time of wave emergence. This finding suggests that endocrine mechanisms leading to emergence, growth and the selection of large follicles are similar between waves in the prepubertal anovulatory period and waves during normal ovulatory cycles in mature cattle.

In the study reported here, concentrations of oestradiol increased significantly in association with ovulatory waves of follicular growth but did not fluctuate in association with non-ovulatory waves, in either the prepubertal or cyclic period. However, oestradiol concentrations did increase with age, in parallel with an increase seen in serum $\mathrm{LH}$ concentrations and LH pulse frequency as the animals neared their first ovulation. There was no increase in FSH secretion as puberty approached in agreement with observations of Gonzalez-Padilla et al. (1975). It, therefore, appears that the secretion of FSH during sexual maturation is not the limiting factor preventing the first ovulation, but that an increase in LH secretion is needed, and that it is only during periods of increasing LH pulse frequency, during the follicular phase of cycles or the late prepubertal period, that follicles increase oestradiol production.

Throughout the prepubertal period, oestradiol acts with strong negative-feedback effects to suppress LH pulse frequency. The reason for the coincident increase in oestradiol and LH secretion seen in our study as the first ovulation approached is therefore unclear. The gonadostat hypothesis (Ramirez and McCann, 1963) suggests that in the later stages of sexual maturation the responsiveness of the hypothalamopituitary unit to oestradiol decreases, allowing increased LH secretion; this in turn stimulates an increase in oestradiol production. In rats and primates, the maturation of a central drive for gonadotrophin secretion was considered to be the major component of the process of sexual maturation (Ojeda, 1991). The endocrine mechanisms giving rise to enhanced $\mathrm{LH}$ secretion before the first ovulation in domestic species are unclear. However, across all species, an increase in LH secretion 
is necessary to induce cyclicity; how this is achieved may vary between species.

In conclusion we have described hormonal and follicular changes preceding the first ovulation, the subsequent short ovulatory cycle, and a cycle of normal duration in heifers. In the 12 weeks preceding the first ovulation, or in the subsequent ovulatory cycles, there were no changes in the maximum diameter of the dominant or largest subordinate follicles, or in dominant follicle growth and regression rates. During the late prepubertal period, the emergence of waves of follicles were associated with peaks in FSH concentrations. Hence, there were no dramatic changes in follicle growth as the time of first ovulation approached, and endocrine mechanisms controlling follicle growth, which were similar to those in adult cows, were in place before puberty.

The authors thank S. J. Cook for technical assistance, W. M. Kerr and staff for care and management of the animals, and NIDDK and USDA for provision of the purified hormone. A. C. O. Evans is grateful for support from the College of Graduate Studies and Research, University of Saskatchewan. This research was funded by a Natural Sciences and Engineering Research Council of Canada grant to N. C. Rawlings.

\section{References}

Adams GP, Matteri RL, Kastelic JP, Ko JCH and Ginther OJ (1992) Association between surges of follicle-stimulating hormone and the emergence of follicular waves in heifers Journal of Reproduction and Fertility 94 177-188

Adams GP, Evans ACO and Rawlings NC (1994) Follicular waves and circulating gonadotrophins in 8-month old prepubertal heifers Joumal of Reproduction and Fertility 100 27-33

Berardinelli JG, Dailey RA, Butcher RI and Inskeep EK (1979) Sources of progesterone prior to puberty in beef heifers Journal of Animal Science $\mathbf{4 9}$ $1276-1280$

Day ML, Imakawa K, Garhia-Winder M, Zalesky DD, Schanbacher BD, Kittok RJ and Kinder JE (1984) Endocrine mechanisms of puberty in heifers: estradiol negative feedback regulation of luteinizing hormone secretion Biology of Reproduction $31332-341$

Day ML, Imakawa K, Wolf PL, Kittok RJ and Kinder JE (1987) Endocrine mechanisms of puberty in heifers: role of hypothalamo-pituitary estradiol receptors in the negative feedback of estradiol on luteinizing hormone secretions Biology of Reproduction 37 1054-1065

Desjardins C and Hafs HD (1969) Maturation of bovine genitalia from birth through puberty Journal of Animal Science 28 502-507

Dodson SE, McLeod BJ, Haresign W, Peters AR and Lamming GE (1988) Endocrine changes from birth to puberty in the heifer Journal of Reproduction and Fertility 82 527-538

Erickson BH (1966) Development and senescence of the postnatal bovine ovary Joumal of Animal Science $25800-805$
Evans ACO, Currie WD and Rawlings NC (1992) Effects of naloxone on circulating gonadotrophin concentrations in prepubertal heifers Journal of Reproduction and Fertility 96 847-855

Gonzalez-Padilla E, Wiltbank JN and Niswender GD (1975) Puberty in beef heifers. I. The relationship between pituitary, hypothalamic and ovarian hormones Journal of Animal Science 40 1091-1104

Ginther OJ, Kastelic JP and Knopf L (1989) Composition and characteristics of follicular waves during the bovine estrous cycle Animal Reproduction Science $20187-200$

Joseph IBJK, Currie WD and Rawlings NC (1992) Effects of time after ovariectomy, season and oestradiol on luteinizing hormone and follicle-stimulating hormone secretion in ovariectomized ewes Journal of Reproduction and Fertility 94 511-523

Kastelic JP, Bergfelt DR and Ginther OJ (1990) Relationship between assessment of the corpus luteum and plasma progesterone concentrations in heifers Theriogenology 33 1269-1278

Kinder JE, Day ML and Kittok RJ (1987) Endocrine regulation of puberty in cows and ewes Journal of Reproduction and Fertility Supplement 34 167-186

Knopf L, Kastelic JP, Schallenberger E and Ginther OJ (1989) Ovarian follicular dynamics in heifers; test of two-wave hypothesis by ultrasonically monitoring individual follicles Domestic Animal Endocrinology 6 111-119

Lutz JB, Rampacek GB, Kraeling RR and Pinkert CA (1984) Serum luteinizing hormone and estrogen profiles before puberty in the gilt Journal of Animal Science 58 686-691

Merriam GR and Wachter KW (1982) Algorithms for the study of episodic hormone secretion American Journal of Physiology 243 E310-E318

Ojeda SR (1991) The mystery of mammalian puberty: how much more do we know? Perspectives in Biology and Medicine 34 365-383

Perry RC, Corah LR, Kiracofe GH, Stevenson IS and Beal WE (1991) Endocrine changes and ultrasonography of ovaries in suckled beef cows during resumption of postpartum estrous cycles Joumal of Animal Science 69 2548-2555

Pierson RA and Ginther OJ (1988) Ultrasonic imaging of the ovaries and uterus in cattle Theriogenology 29 21-38

Ramirez DV and McCann SM (1963) Comparison of the regulation of luteinizing hormone $(\mathrm{LH})$ secretion in immature and adult rats Endocrinology $\mathbf{7 2}$ 452-464

Rawlings NC and Churchill IJ (1990) Effects of naloxone on gonadotrophin secretion at various stages of development in the ewe lamb Joumal of Reproduction and Fertility 89 503 -509

Rawlings NC, Jeffcoate IA and Rieger DL (1984) The influence of estradiol 17- $\beta$ and progesterone on peripheral serum concentrations of luteinizing hormone and follicle stimulating hormone in the ovariectomized ewe Theriogenology 22 473-488

Roche JF and Boland MP (1991) Turnover of dominant follicles in cattle of different reproductive states Theriogenology 35 81-90

Savio JD, Keenan L, Boland MP and Roche JF (1988) Patterns of growth of dominant follicles during the oestrous cycle of heifers Journal of Reproduction and Fertility 83 663-671

Sirois J and Fortune JE (1988) Ovarian follicular dynamics during the estrous cycle in heifers monitored by real-time ultrasonography Biology of Reproduction 39 308-317 